\title{
Neste fascículo dos Arquivos Brasileiros de Ciências da Saúde
}

Ricardo Peres do Souto

Neste fascículo dos Arquivos Brasileiros de Ciências da Saúde:

Evo e colaboradores (página 6) utilizam metodologia bem estabelecida nos estudos sobre poluição atmosférica para a demonstração dos seus efeitos deletérios sobre a saúde da população, mais especificamente, a ocorrência de insuficiência cardíaca congestiva em idosos, confirmando e reforçando a literatura existente;

Baraldi e Souto (página 10) analisam a demanda na estratégia de Saúde da Família, espaço esperado pela política pública para reorientar o modelo de atenção à saúde, identificando fragilidades no modo de operar a proposta de acolhimento;

Squassoni e colaboradores (página 18) estudam o efeito da reabilitação pulmonar em pacientes com DPOC, trazendo como novidade a inclusão de tabagistas e sugerindo a possibilidade de um programa de exercícios físicos auxiliar na cessação do tabagismo;

Korkes e colaboradores (página 24) avaliam os encaminhamentos de pacientes para um serviço de Urologia, discutindo atendimento primário, referenciamento ao especialista e contra referenciamento e contribuindo para a reflexão sobre a realidade do nosso sistema público de saúde;

Manso e colaboradores (página 29) relatam a busca por novas formas de avaliar as alterações do biomarcador CA19-9 associadas ao câncer colorretal e a tentativa de relacioná-las à gravidade da doença;

Meyer e colaboradores (página 35) ressaltam as potencialidades da Magnetoterapia para um profissional específico (fisioterapeuta), mas lançando mão de abordagem multidisciplinar;

Ferreira e colaboradores (página 40) revisam a interessante história da febre amarela no Brasil e destacam aspectos relacionados à vacinação; Souza e Pinhal (página 48) organizam informações selecionadas sobre a participação de proteoglicanos e glicosaminoglicanos em processos fisiológicos, contribuindo para esclarecer a importância biológica destes compostos;

Juc e colaboradores (página 55) exploram os mecanismos de funcionamento do sistema urinário inferior e as interferências que lesões no sistema nervoso podem gerar sobre sua operacionalidade.

Boa leitura. 